\title{
BMJ Open Resisting recommended treatment for prostate cancer: a qualitative analysis of the lived experience of possible overdiagnosis
}

\author{
Kirsten McCaffery, ${ }^{\oplus 1}$ Brooke Nickel, ${ }^{\oplus 1}$ Kristen Pickles, ${ }^{\oplus 1}$ Ray Moynihan, ${ }^{1,2}$ \\ Barnett Kramer, ${ }^{3}$ Alexandra Barratt, ${ }^{1}$ Jolyn Hersch ${ }^{\oplus 1}$
}

To cite: McCaffery K, Nickel B, Pickles K, et al. Resisting recommended treatment for prostate cancer: a qualitative analysis of the lived experience of possible overdiagnosis. BMJ Open 2019;9:e026960. doi:10.1136/ bmjopen-2018-026960

\section{- Prepublication history and} additional material for this paper are available online. To view these files, please visit the journal online (http://dx.doi. org/10.1136/bmjopen-2018026960).

Received 3 0ctober 2018 Revised 28 January 2019 Accepted 28 March 2019

Check for updates

(C) Author(s) (or their employer(s)) 2019. Re-use permitted under CC BY-NC. No commercial re-use. See rights and permissions. Published by BMJ.

${ }^{1}$ School of Public Health, The University of Sydney, Sydney, New South Wales, Australia

${ }^{2}$ Faculty of Health Sciences and Medicine, Bond University, Robina, Australia

${ }^{3}$ National Cancer Institute

Division of Cancer Prevention, Bethesda, Maryland, USA

Correspondence to Dr Kirsten McCaffery; kirsten.mccaffery@sydney. edu.au

\section{ABSTRACT}

Objective To describe the lived experience of a possible prostate cancer overdiagnosis in men who resisted recommended treatment.

Design Qualitative interview study

Setting Australia

Participants 11 men (aged 59-78 years) who resisted recommended prostate cancer treatment because of concerns about overdiagnosis and overtreatment. Outcomes Reported experience of screening, diagnosis and treatment decision making, and its impact on psychosocial well-being, life and personal circumstances. Results Men's accounts revealed profound consequences of both prostate cancer diagnosis and resisting medical advice for treatment, with effects on their psychological well-being, family, employment circumstances, identity and life choices. Some of these men were tested for prostate-specific antigen without their knowledge or informed consent. The men felt uninformed about their management options and unsupported through treatment decision making. This often led them to develop a sense of disillusionment and distrust towards the medical profession and conventional medicine. The findings show how some men who were told they would soon die without treatment (a prognosis which ultimately did not eventuate) reconciled issues of overdiagnosis and potentia overtreatment with their own diagnosis and situation over the ensuing 1 to $20+$ years.

Conclusions Men who choose not to have recommended treatment for prostate cancer may avoid treatmentassociated harms like incontinence and impotence, however our findings showed that the impact of the diagnosis itself is immense and far-reaching. A high priority for improving clinical practice is to ensure men are adequately informed of these potential consequences before screening is considered.

\section{INTRODUCTION}

The concept and reality of overdiagnosis and overtreatment of prostate cancer is now widely accepted. Autopsy studies in men who died of causes other than prostate cancer show that there is a substantial reservoir of non-progressive prostate cancer in
Strengths and limitations of this study

- This qualitative study used interviews to explore the stories of men, diagnosed with prostate cancer, who self-identified as resisting clinical recommendations for prostate cancer treatment.

- There are considerable challenges to identifying individuals with cancer who have not been treated and show some awareness of the issues of overdiagnosis; our study is the first to achieve this in prostate cancer.

- Our sample was small and the men were well educated, economically successful and had high health literacy, which may have provided increased confidence, means and capacity to challenge medical advice.

the general male population that increases with age. ${ }^{1}$ Screening for prostate cancer may therefore detect non-lethal cancers, leading to overdiagnosis and overtreatment. A precise estimate of the extent of overdiagnosis in any screening programme is difficult, but estimates from the two largest prostate screening trials suggest that between $17 \%$ and $50 \%$ of prostate cancers are overdiagnosed. ${ }^{2}$ Overdiagnosed cancers are by definition cancers that are not destined to cause morbidity or mortality so men with these cancers can only be harmed by early detection and unnecessary treatment. ${ }^{3}$ Extensive evidence suggests that common, long-lasting harms triggered by the prostate-specific antigen (PSA) screening test counterbalance or even outweigh the benefits (which, if they occur, are delayed 10-15 years or more), and most international medical bodies advise against PSA screening. ${ }^{245}$ Yet a significant number of men still undergo PSA testing, ${ }^{67}$ many of whom are poorly informed.

Once men receive an elevated PSA test result, a biopsy may be performed. Biopsies have a high probability of finding prostate 
cancer that may never have caused clinical symptoms ${ }^{89}$ and once diagnosed, many men with low-risk, localised cancer undergo active treatment immediately. ${ }^{10}$ Surgery (radical prostatectomy) is the most frequent treatment method used among men with clinically localised prostate cancer in Australia. ${ }^{11}$ Mainstay active treatments for prostate cancer such as surgery, radiation therapy and hormone therapy can result in serious adverse consequences including impotence and incontinence (with surgery) and bowel problems (with radiation therapy). ${ }^{12}$

To reduce the harms of overtreatment, active surveillance (AS) is endorsed as a management option by a number of professional societies for men who present with low-risk $(\mathrm{PSA}<10$, Gleason $\leq 6$, clinical stage T1-T2) prostate cancer. ${ }^{13-16}$ AS involves closely monitoring the tumour (via clinical examinations, imaging, PSA tests and prostate biopsies) and acting with curative intent if the disease progresses. A 10-year study of $>1500$ men with screen-detected localised prostate cancer found no difference in death rates between men who received a radical prostatectomy or radiation and those who monitored their disease. ${ }^{17}$ Numerous qualitative studies have explored men's views regarding the acceptability of an AS management approach, as well as men's experiences after opting for AS. ${ }^{18-22}$ However, we know of no studies that have explored men's choice not to follow any recommended management approach, and the consequences for them of so doing.

This study reports on the experiences of men diagnosed with prostate cancer between 1 and 20 years ago. They declined clinical recommendations for immediate treatment including radical prostatectomy and radiotherapy and elected to devise and adopt their own management strategies for their prostate disease. Despite the medical advice they received at the time of diagnosis these men are still alive and are coming to terms with a cancer diagnosis and medical advice that implied imminent death if the recommended (mostly surgical) treatment was not followed. Their narratives provide insight into the hidden experience of a potentially 'unnecessary' diagnosis of prostate cancer, including the psychological and social experiences of declining treatment advice, living with a slow growing or inconsequential cancer and maintaining physical and mental health.

\section{METHODS \\ Design}

This study used qualitative interviews to explore the stories of men, diagnosed with prostate cancer, who self-identified as resisting clinical recommendations for prostate cancer treatment.

\section{Patient and public involvement}

The research question was informed by two consumers' personal experience of being diagnosed with prostate cancer. The consumers/patients provided advice on the study design and results and were involved in study recruitment. The findings of the study will be disseminated to all study participants.

\section{Participants and recruitment}

Eleven men initially diagnosed with localised prostate cancer, located in three states in eastern Australia (New South Wales, Victoria and Queensland).

Men were eligible to participate in the study if they had received a biopsy-confirmed diagnosis of prostate cancer and initially declined clinical recommendations for treatment. Participants were included if they indicated the following to the interviewer: (1) awareness of the issues of overdiagnosis and/or overtreatment, (2) expressed doubt about their recommended treatment or their management decision and (3) had drawn a connection between their personal situation and issues of overdiagnosis/ overtreatment.

Most participants were recruited via an information and support group (this group was organised by one of the participants and is not connected to a charity group or any entity that is part of the medical establishment) for men with prostate cancer seeking non-surgical management. Two further eligible participants independent of the support group were identified after they emailed members of the research team or their academic networks to seek advice about prostate cancer. Researchers presented information about the study to potential participants. All potentially eligible men were sent/given an Expression of Interest form. Those who returned the form were contacted to arrange an interview. They were invited to share study information with other men (snowball sampling). All participants provided written informed consent prior to the interview. All men who expressed interest in the study and met the inclusion criteria agreed to be interviewed and were included in the study.

\section{Data collection}

An interview guide (online supplementary appendix 1) was developed by the research team who have expertise in psychology, health communication, public health and overdiagnosis. Interviews were conducted by three academic researchers $(\mathrm{KM}, \mathrm{BN}, \mathrm{JH})$ trained in qualitative research methods between November 2015 and March 2016. The interviewers had no immediate personal or professional experience with prostate cancer or PSA screening, and do not work with men who have prostate cancer. Interviews were conducted at participants' homes, their offices, the University of Sydney or Skype (4/11). We interviewed as many men as possible who met the inclusion criteria. Since this is a difficult sample to identify, we cannot state that we reached thematic saturation. ${ }^{23}$ Interviews lasted between 22 and $70 \mathrm{~min}$ and were audio-recorded and transcribed verbatim. All clinical data were self-reported.

\section{Analysis}

The analysis was an iterative process and commenced during data collection. Researchers conducted a thematic 
Table 1 Participant characteristics and main reasons expressed for resisting recommended treatment

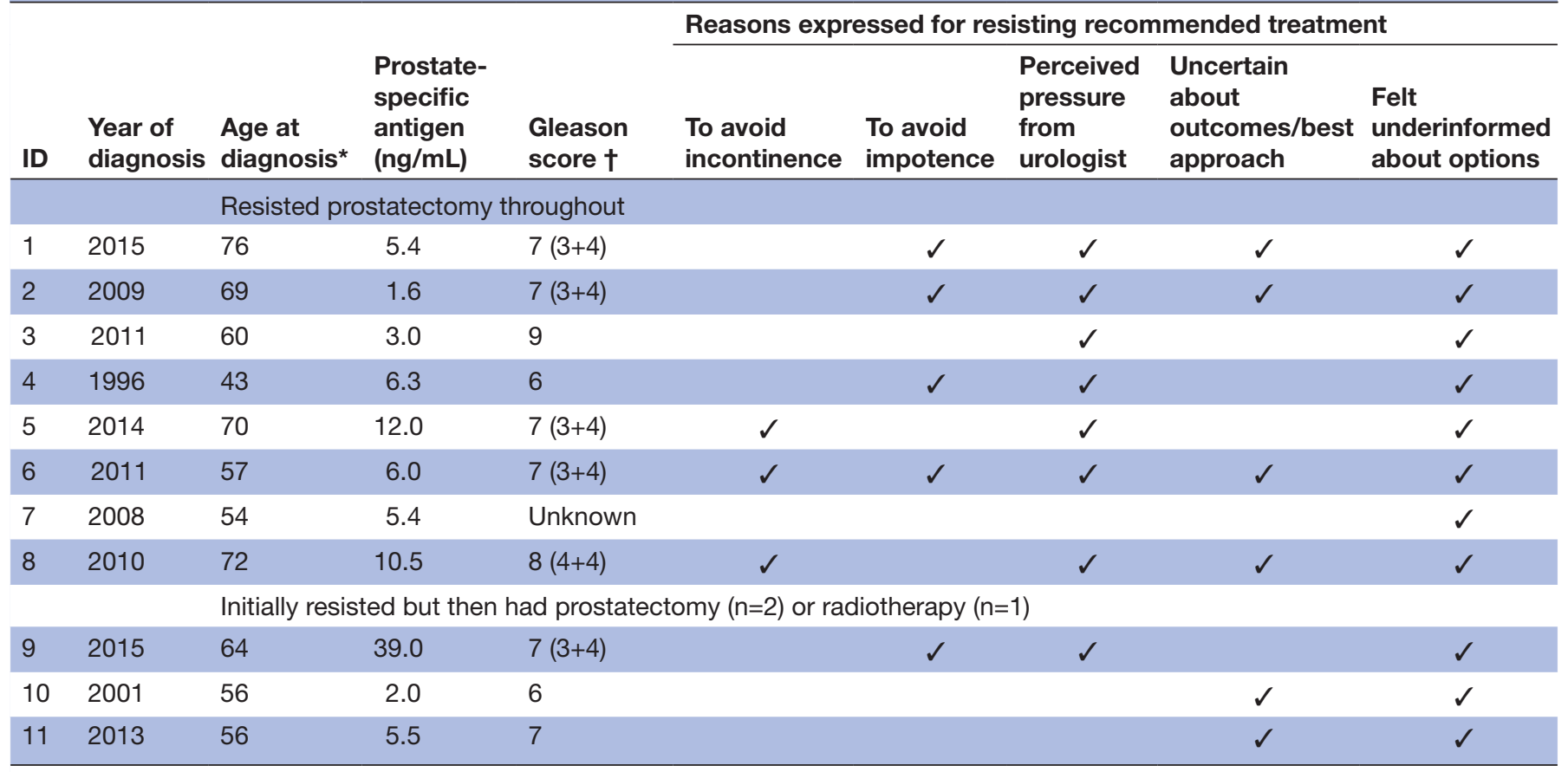

† gleason grade included when reported by participant. Blank if unknown.

analysis, aiming to capture the diverse feelings and views expressed by the men. The interviewers (KM, BN, JH) met regularly to discuss salient observations from their interviews, which formed the basis of the initial coding framework. All interviewers read a subset of transcripts and discussed and revised the coding framework. Once the framework was finalised, BN coded all interviews using Framework Analysis in Excel. ${ }^{24} \mathrm{KM}$ iteratively checked the coding framework within and across themes and participants. Themes were summarised and checked by $\mathrm{JH}$ and KP who added further interpretation and insights. Four case studies are presented in the results which were selected to represent a range of experiences of diagnosis and decision making among the sample. Written consent was obtained from the relevant parties for the publication of the case studies.

\section{RESULTS}

The 11 participants were aged $59-78$ years at the time of interview and 43-76 years (average age 62 years) when they were diagnosed with prostate cancer (table 1). In Australia, the mean age of prostate cancer diagnosis is 69 years. One man received a PSA test after reporting urinary symptoms, the other 10 were asymptomatic when tested. Time since diagnosis: $<2$ years $(n=3), 3-9$ years $(n=6), 10$ years or more $(n=2)$. The men's self-reported PSA level at the time of diagnosis was between 1.6 and 39.0 with Gleason scores between 6 and 9. Nine men held a bachelor's degree or above and one was a medical specialist; none had expertise in complementary medicine. All men initially declined the treatment recommended to them, which was surgery (prostatectomy) for 10/11 men.

The men's accounts demonstrated broad and significant implications resulting from resisting professionally recommended treatment for prostate cancer. Here, we report on the men's reasoning for resisting, its impact on their personal lives, feeling unsupported and their response to the experience, including distrusting conventional medicine and questioning decisions made (table 2). Four case studies are included which capture the individual stories of a selection of men.

\section{Men's resistance to recommended treatment}

The most common explanations that the men gave for initially resisting prostatectomy were feeling underinformed about their options and, at the same time, feeling pressured by their urologist to undergo surgery immediately (table 1 and 2). These factors together generated considerable uncertainty among the men. Several men diagnosed within the last $1-5$ years said they were offered little choice beyond surgery. A number of men expressed fear of suffering impotence or incontinence following surgery, and generally felt more strongly about avoiding the risk of suffering one more than the other. Some were more familiar with the potential negative consequences of prostatectomy via a family member or friend who had undergone surgery and wanted to avoid similar outcomes.

The men's accounts indicated varied awareness and understanding of overdiagnosis and overtreatment. Most were familiar with the general concepts including the fact that a significant number of men live with untreated and 
Table 2 Summary of key findings with illustrative quotes

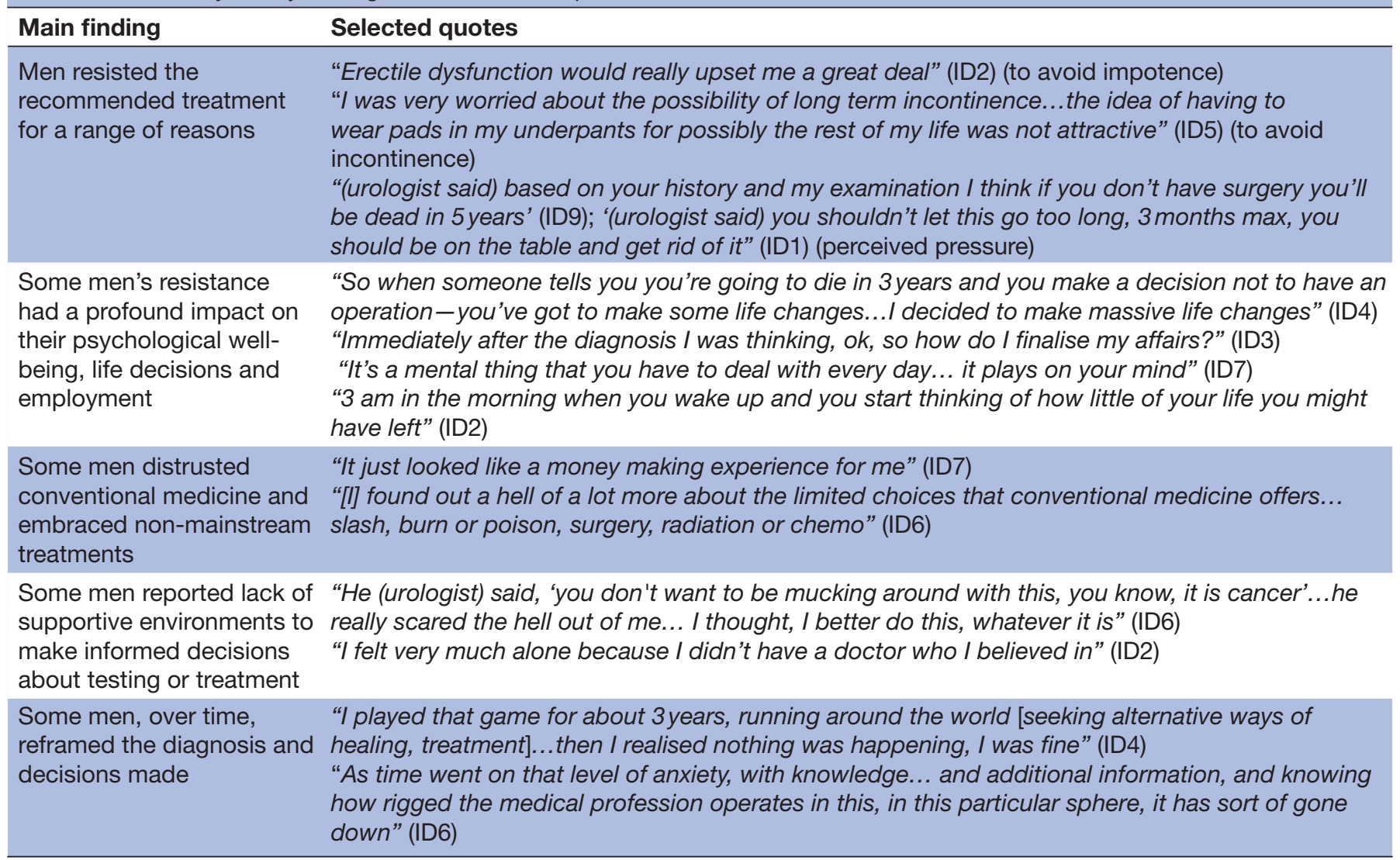

undiagnosed prostate cancer, and that surgery might be unnecessary, costly and result in undesirable outcomes. Some men had very sophisticated knowledge. A few men explicitly stated that they resisted the recommended surgery specifically because of concerns about overdiagnosis and were aware of debates among the medical profession about these issues. Some only encountered the concept of overdiagnosis following their own extensive researching after their diagnosis; one participant said that he read ten books on the subject.

\section{Men's resistance had a profound impact on their} psychological well-being, life decisions and employment

The men resisted treatment even though most of them described experiencing considerable pressure to take urgent action. Several $(n=4 / 11)$ were told that they would be dead in the next couple of years unless they had a prostatectomy and felt threatened and frightened by their impending death. Some of the men, immediately after their diagnosis, began to prepare for their death by 'finalising their affairs', including extracting themselves from business partnerships leading to loss of income and change in financial circumstances. But the decision not to have the surgery had similarly profound effects on their lives as the actual cancer diagnosis. Two men were divorced following their diagnosis and attributed this as a major cause. One man directly stated that his marriage became untenable because his wife did not support his decision not to have a prostatectomy. Some men left work entirely or modified their employment to make time to research and focus on their health and/or to pursue alternative treatments overseas.

I had difficulty dealing with work and my other commitments...I gave it all up, walked out! I decided to walk out of my business... I decided to walk out of my partnership... (ID4)

Resisting intervention was an intensely psychological experience. High anxiety and doubt, a sense of 'playing with fire', commonly persisted for many years after their diagnosis and decision to resist and continued to be experienced on a daily basis for some. The worst possible consequences of resisting, such as cancer spread and/or death, played heavily on the men's minds.

I still doubt whether I've done the right thing, but so far so $\operatorname{good}(\mathrm{ID} 2)$

\section{Case Study 1: Bob*}

Bob had been living with a diagnosis of prostate cancer for 7 years at the time of interview, and was diagnosed aged 69 years. Bob's doctor began ordering annual PSA tests when he was 65, and he went along with it because the potential implications of having a PSA test were never explained to him. After a few years, his PSA was slightly raised (to 1.6), and the doctor recommended a biopsy, which he had. He described having blood in his urine and a loss of 
sensitivity following the biopsy, which was unexpected because he did not know anything about the possible side effects beforehand. Bob was diagnosed with prostate cancer, Gleason score 7. He reported that the urologist told him that he would be dead in 3 years if he did not have his prostate removed immediately, and said he could perform the surgery a few days away. Bob described feeling immobilised, not being able to think; 'dead in 3years?' That's all I could think of. He had just been told he might miss out on seeing his grandchildren grow up. He was already aware of the risks of prostate surgery and was very concerned about erectile dysfunction. When Bob asked for a second opinion, he was referred to his urologist's business partner, which prompted him to embark on a quest for alternative treatments himself. He did an enormous amount of independent research-reading nothing else but medical books for 4 or 5 years, sent his pathology to interstate and international specialists (at enormous expense), and then flew to New York for prostate scans. It was very consuming, in terms of time and emotionally. Bob withdrew from part of his business because he couldn't work as much, alongside studying medical texts. He experienced difficulty sleeping throughout. He returned to a radiologist in New York several more times to monitor any cancer progression. According to these scans, Bob's prostate cancer has not changed in any way in the 7 years since his diagnosis. Yet it has had a long-lasting impact. He continues to suffer sleeplessness, and wonders every couple of days whether he has done the right thing by not going ahead with the recommended treatment. He hopes he can help provide other men with more support to make their own decisions, because this isn't riskless.

\section{Case Study 2: Jim}

Jim was diagnosed with prostate cancer at the age of 54. His story began when he went to his GP for a routine prostate check. The GP performed a digital rectal examination (DRE) but during the procedure, Jim reported that his GP twisted his prostate, which left him hospitalised, in agony, and with long-term side effects. Two years later, he had another DRE and a small nodule was felt by his GP. Jim was referred to a urologist for a biopsy and had his first ever PSA test; his PSA was elevated (5.4). Jim said he suffered terribly from the biopsy, it was very painful and there was blood everywhere, he said if he was more informed he would not have agreed to it. The biopsy showed that a small proportion of 1 of the 12 samples taken had evidence of prostate cancer. The diagnosis was devastating, and it took me a while to get my head around that. Jim was referred to an oncologist and another urologist: he had a good experience with the oncologist, but described his consultation with the urologist as really off-putting, especially when he was booked in for an immediate prostatectomy without any discussion about alternative management options. He began an extensive investigation of his options, hours and hours of research about prostate cancer and its treatment. He gathered information from men in a prostate cancer support group in a similar position, had ultrasounds and MRIs and learnt about overdiagnosis and overtreatment. At the time of the interview, it had been 8 years since Jim had decided not to have a prostatectomy. He monitors his prostate cancer with annual ultrasounds and PSA tests and is very happy with his decision not to have active treatment. However, his decision has had a substantial impact on his life. Jim's wife could not accept his choice not to have the surgery, which ultimately contributed to a debilitating divorce. He defended his approach as considered, evidence-based, not just going willy nilly down the holistic path; yet described the psychological impact of resisting surgery as ongoing, a mental thing that you have to deal with every day...it plays on your mind. He advocated for men to have the opportunity to stop and think about things and go, hang on a second, is this the right thing to do?

*All names have been changed to preserve anonymity. Italics indicate verbatim quotes.

Distrust of conventional medicine and embracing non-mainstream treatments

The men reported feeling disillusioned by conventional management options and medical opinion (table 2). Many of those interviewed felt abandoned by their clinicians, specialists and/or the Australian healthcare system when they resisted the recommended treatment. Some men expressed cynical views of the medical profession and speculated that the unequivocal advice for prostatectomy was driven by financial gain. They felt concerned that they were not getting the full story, from any clinician, about the range of potential management options.

I am profoundly dissatisfied with what I see as the blinkered view of possibilities offered ... and the incapacity of these people to consider anything outside their carefully regulated areas of expertise. (ID5)

In response, they pursued extensive additional testing and imaging and dedicated enormous time and energy to researching other available options. Almost all of the men had actively sought out and embraced an alternative management strategy outside of the mainstream system. For some this involved herbal supplements, Chinese medicine, or major dietary and lifestyle changes. For several others, it involved visiting international clinics and having ongoing tests and unproven treatments that were vastly expensive (eg, hyperthermia: targeted heat therapy applied to the area of the prostate). Men reported hearing about alternative treatments such as hyperthermia from other men in the support group. Several suffered pain and discomfort from their procedures, but still perceived them as a far better alternative than prostatectomy. 
(Hyperthermia) not an entirely pleasant experience but not nearly as debilitating as the radical (prostatectomy) (ID5)

\section{Lack of supportive environment to make informed decisions about testing or treatment}

It became evident across the interviews that the men felt they were offered limited, if any, time or resources to encourage or enable them to make an informed decision about either PSA testing or treatment. The majority of men were not familiar with what a PSA screening test was and received no information prior to being screened; some did not even know they had been screened until they were told their PSA was abnormal.

I had no idea what a PSA test was. The doctor said 'it's time' and I went along with it (ID2); I wouldn't even have known what a prostate was about (ID10)

A number of the men shared stories of urologists who scheduled their prostatectomies in the same appointment that their diagnosis was given. Only one participant was advised, after seeking a second opinion, to take his time in making a decision about surgery, which he said was very helpful at the time. Urologists were often perceived to be surgery-focused and with little consideration of what the individual man might want or need from the consultation. The men perceived little support or reassurance and noted an environment that provided little encouragement for them to ask questions or express individual priorities. They described real concerns that they wanted to be heard-that biopsies and surgery might spread cancer, fear of the side effects of surgery, being treated unnecessarily-but reported feeling that there was little possibility of discussing such matters with their urologist.

Men reported discussing their decision to resist the recommended treatment with family (mostly wives/partners and adult children) and friends. Some stated that their decision to refuse treatment led to some conflict in their relationships while others described their partners as being very supportive. Three of the men reported feeling reassured of their decision not to have surgery after making contact with other men who had made similar decisions (but implied their decision had been made before discussing with others).

I'm grateful that I came across-that I did the research and came across the people who are in the same boat. (ID7)

\section{Reframing the diagnosis and decisions made}

At the time of the interview, 8 of the 11 men had continued to resist the recommended prostatectomy, suffering no physical morbidity from prostate cancer. Several reflected on their personal situation and increasing awareness that their cancer had not progressed and may not ever do so, hence might not be the life-threatening scenario that had been presented to them. A number questioned whether seeking out alternative ways of healing and treatment had helped or whether they would have had the same outcome regardless.

I played that game for about 3years, running around the world [seeking alternative ways of healing, treatment]... then I realised nothing was happening, I was fine. (ID4)

I've known for five and a half years that I've got cancer in me, and I'm still living, walking around, no side effects, no nothing... perhaps I will be ok. (ID8)

Some men explicitly considered the relevance of the overdiagnosis/overtreatment debate to their circumstances. One medically trained participant was highly informed about issues of overdiagnosis and overtreatment. He had reluctantly agreed to having a PSA test-a 'flawed screening test' - as an insurance requirement, after resisting screening for many years. This man, who had a prostatectomy after a very high PSA reading, wondered if he is one of the ones overdiagnosed or whether his diagnosis and surgery saved his life.

There's a part of me that wonders did I fuck myself up because I waited three and a half years or did I fuck myself up because I had the cleanout...I'll never know. If I die in the next 5 years of metastasis then I'll know I waited too long... again, I'll never know. I mean, if I die of something else, I won't know if this never would've spread anyway, or they saved my life. (ID9)

He indicated that he had spent considerable time questioning and reviewing the decisions he had made.

I had lost a considerable amount of weight...I went to see the urologist and he said... you know, because of your PSA, he didn't say because you waited but it was implied, that maybe if I had addressed this three and a half years ago... (ID9)

\section{Case Study 3: Ted}

Ted was diagnosed with prostate cancer (Gleason 6) at 56 years, 15 years before this interview. He had never had a PSA test until he was referred to a urologist for a urinary tract infection. He admitted that he didn't even know what the prostate was. A PSA of 2.0 prompted a biopsy. When the urologist told Ted that the biopsy had detected prostate cancer, he implied that it was bad, he was pretty grim, and wanted to arrange urgent treatment. Ted was very concerned. In hindsight he has realised that he (urologist) told me things that were not true.... that probably it'd spread. He received anti-hormonal injections (from which he suffered massive hot flushes) in anticipation of delayed surgery, because he was in the process of moving back to Australia after living overseas for some years. When he returned, Ted consulted multiple urologists about his treatment options, all with vastly differing opinions. Despite being told by one urologist that he would be dead within 5 years, he decided not to go ahead with surgery, I wasn't keen to have any intervention if it wasn't necessary...I didn't have a lot of problem living with cancer. Instead, at the advice of a 
non-interventionist urologist, he monitored the tumour via biopsies and PSA, which made his first urologist angry. Ted did eventually have treatment: first, brachytherapy, because it did not seem to be very invasive. It was painless and without side effects. Four years later, he had external beam radiation, again with minimal side effects. After 14 years of living with prostate cancer, Ted finally had a prostatectomy at the advice of his urologist after his PSA doubled (PSA increased from 2 to 4), despite originally being firmly against intervention. He describes the flow on effects that can eventuate from a positive PSA test: you're damned if you do and it's a damned if you don't. You know, because you're in a dilemma and you really don't know how serious this dilemma is. '...I stayed with it—well I hadn't stayed with it I had it for 14 years and I eventually did have the treatment...I did have to have it in the end'. He said over the 14 years he had plenty of time to find out about the possible side effects of surgery, most of which he didn't want. Following the prostatectomy, he had a lot of anal pain, lacks faecal control, and is impotent. He doesn't regret postponing the surgery. But if you come to me in 5 years' time and I'm almost dead because I didn't have the surgery earlier I might have a different idea, mightn't I? ... 'I hope I have nothing to regret, we'll see in 3 or 4 years' time but I'm getting past the 5 years that (the urologist) reckoned I would have' (to live).

Another man strongly resisted the recommended management for a number of years following an elevated PSA result due to awareness of the harms of overdiagnosis but then reported having developed secondary cancer. He subsequently had mixed views on overdiagnosis because he is living with a progressed cancer that may have benefited from earlier detection. He questioned whether he should have agreed to further testing and treatment sooner.

All that overdiagnosis is to try and save the one, turns out I'm the one so, I have mixed views on it. (ID11)

Both men showed signs of self-blame for their decision-making. The uncertainty about whether the decisions they had made were the right ones seemed to play heavily on their minds and was ultimately unresolvable.

\section{Case study 4: Peter}

Peter was diagnosed with prostate cancer (Gleason 7) in 2013 at 56 years. He had for many years resisted having a biopsy, which was recommended to him following an elevated PSA (but normal DRE). He described a urologist trying to force me to have a biopsy against my better judgement. He felt that the information about the wisdom of having a biopsy done simply on the basis of a rising PSA was conflicting, and had heard concerns about overtesting and overdiagnosis on the radio. He recalled at the time thinking I probably didn't have a serious problem...I thought the odds were still in my favour. Instead, Peter chose to undergo ultrasounds of his prostate and had a new procedure (laser ablation) in New York: a radical new treatment having great success. He considered it his best shot at having the treatment done and dusted. It cost US\$30000 (which seemed like a good bet at the time...In hindsight I'd love to get my money back if I could) and was extremely uncomfortable and undignified, intrusive. Initially, the specialists pretty well declared the whole process a success, and he was told to go home and you shouldn't have any more worries. However, 12 months later his PSA had risen to 24, so I clearly had a bit of a problem. A full body CAT scan revealed a suspicious area in his hip, which was potentially a secondary cancer. The specialist's recommendation was for Peter to have hormone treatment-which he really struggled with - and then fairly aggressive radiation treatment. A radical prostatectomy was not an option after he had had the laser treatment. His thought process at the time was, I'd pursued the sort of alternative treatment path thinking at the time that it was unlikely I had a severe problem anyway... I was sort of just being a little cautious. But, it turns out I was in that small percentage that had a serious growth. The alternative treatment hadn't worked. By this stage he had realised that he couldn't afford to screw around with this anymore, his efforts trying to manage my own prognosis had been unsuccessful and he resorted to finding the best specialist he could. Peter described the whole process as a rollercoaster. At the time of interview, it had been 2 years since his radiation therapy. He continues to have side effects including some impotence and rectal bleeding. Peter had to reduce his working hours, it has a real impact, a big impact. He suffers from anxiety attacks and described sometimes being almost petrified with fear. The prostate cancer causes significant worry, I'm still concerned that it's probably going to get me...I suspect that it's a matter of time. Peter admitted that with hindsight he would have changed my course of action... clearly I should have had a biopsy done. He believes that it was a good decision to leave the first urologist and not to have had a biopsy straight away, but would have sought better specialist advice sooner, and had a prostatectomy if it was recommended. Peter continues to believe that there is some truth in the overdiagnosis and overtreatment argument, but turns out I'm in that very small percentage... all that overdiagnosis is to try and save the one, turns out I'm the one, so I have mixed views on it...I'd be in much more serious trouble had I not had the treatment.

\section{DISCUSSION}

This study provides important, relevant insight into the lived experience of possible overdiagnosis. It reveals the substantial and sustained burden on men's lives as they continue to live with a potentially inconsequential cancer diagnosis alongside their decision to decline recommended treatment. Such accounts are rarely reported in the literature, hidden in part because we are mostly unable to identify individuals who have been feel they may have been overdiagnosed, given that it is rare to 
leave cancer untreated. Importantly, these men's views contrast with beliefs of many patients with cancer that their diagnosis was life-saving or life affirming and reveal the profound negative psychosocial impact of diagnosis.

Clinicians have traditionally underappreciated the adverse impact of prostate cancer diagnosis and treatments thus resulting in limited visibility of these effects in the medical literature until recent years. ${ }^{12526}$ Previous work with clinicians shows that a strong driver of the continued use of PSA testing is the fear of missing a patient's cancer. ${ }^{27-29}$ However, this fails to recognise the potential downstream consequences on men of unnecessary testing and overdiagnosis.

Particularly notable in this study were two men who had deliberately delayed testing and treatment because of concerns about overdiagnosis and overtreatment. They both eventually, reluctantly, received cancer treatment (one presented symptomatically with a secondary cancer, the other had a dramatic increase in PSA). At the time of interview, they described significant uncertainty and angst about their decision to delay. Both had a very sophisticated understanding of overdiagnosis and recognised that they would never know if they had made the right decision. The guilt, questioning and uncertainty that remains with that knowledge was significant and unresolvable.

For some men in this sample, feeling uninformed and pressurised by specialists were described as more important reasons to resist surgery than avoidance of potential treatment side effects . These findings demonstrate the real-life consequences of violations of the ethical principle of autonomy, with men reporting being tested for PSA without their knowledge and being offered limited information about treatment. This is consistent with existing literature suggesting that many Australian men do not have treatment options for early prostate cancer adequately explained to them, with urgent surgical treatment still frequently encouraged. ${ }^{30}$ Research from the US suggests a similar picture with informed decision-making rare, ${ }^{31}$ even when decision support is provided. ${ }^{32-34}$ Recent findings from the US and Australia similarly suggest shared decision-making around PSA testing and prostate cancer treatment is limited. ${ }^{30} 3335$

Poor public understanding of PSA screening and overdiagnosis is common, ${ }^{36-38}$ and likely exacerbated by lower levels of education and health literacy. ${ }^{39}$ There is evidence that the harms of overdiagnosis and overtreatment are rarely explained to patients. ${ }^{40} 41$ Overdiagnosis is a challenging concept to communicate,${ }^{36}{ }^{42}$ yet studies of prostate screening show that men want to be told about it. ${ }^{43}$ Importantly, some research suggests that informing men about their options early, including the option of conservative treatment, might help mitigate long-term decision regret. ${ }^{44}$ Continued efforts to better communicate, inform and empower men to avoid the implications described in this study are essential.

Men in this study felt inadequately prepared and unsupported from the point of the initial PSA screening test, to biopsy and treatment decision-making. A qualitative study of individuals who self-identified as having an overdiagnosed thyroid cancer and decided not to intervene with surgical treatment revealed similar findings to this study. ${ }^{45}$ Their experience was characterised by feelings of isolation and ongoing anxiety resulting from lack of social and healthcare system acceptance and support for their decision to resist treatment. The view that treatment is always needed and life-saving is normalised such that attitudes contrary to that norm may be dismissed and rejected.

Although this study cannot discern causation, it could be that distrust in conventional medicine may ensue from feeling inadequately informed and unsupported. It is noteworthy that many of the men pursued expensive alternative tests and treatments that have little current supporting evidence of efficacy, with a strong desire to 'do something'. This revelation is not surprising given that a recent Australian study documented increased distress and anxiety in men who opted to monitor their low-risk prostate cancer rather than actively treat it, ${ }^{46}$ and a 5 -year follow-up study found that $23 \%$ of men discontinued AS despite no evidence of cancer progression. ${ }^{47}$

There was a wide range ( 1 to $20+$ years) of time since diagnosis when the interviews took place. These findings should be considered in the context of changes over time and current management of localised prostate cancer. Prostate screening, diagnosis and management strategies have changed rapidly over the years and we recognise that shifting policy, service provision and information resources (eg, internet) over that time might have impacted on men's experiences and perceptions reported here. Changing technologies and new knowledge have advanced the field. Active surveillance, which is now endorsed as a management option for men with low-risk disease, was not a common option when some men in this study were first diagnosed. Uptake of AS for low-risk prostate cancer is increasing in Australia with current estimates indicating around 36\% of men with low-risk prostate cancer accept it. ${ }^{48}$ Importantly, several recently diagnosed men in our sample reported that AS was not discussed with them as a potential option.

\section{Strengths and limitations}

To our knowledge, this is the first study to document how men diagnosed with prostate cancer reconcile issues of overdiagnosis and overtreatment and make sense of these issues in relation to their own situation. There are considerable challenges to identifying individuals with cancer who have chosen not to be treated and show some awareness of the issues of overdiagnosis. Our study is the first to achieve this in prostate cancer.

Our sample was small and the men were well educated, economically successful and had high health literacy. This may have provided increased confidence and capacity to challenge medical advice, and to seek out and understand complex health information and concepts such as overdiagnosis and overtreatment. Recent evidence suggests that 
men with higher education and income in Australia and the USA are more likely to have PSA testing and therefore be diagnosed with prostate cancer. ${ }^{49}{ }^{50}$ Our participants were initially recruited through a support group founded by men who had resisted surgical management of prostate cancer. Although resisting treatment altogether may not be a common experience, the concerns and reactions of these men to their situation would likely be salient for the many men with localised prostate cancer who find themselves facing this unpleasant dilemma. Many of the cancer-related fears and uncertainties expressed by the men in our sample are similar to those reported in studies from North America ${ }^{51}{ }^{52}$ and are likely to transcend international borders. They therefore provide important leads for further research internationally.

We note that recall bias is possible given that it had been many years since diagnosis for some of the men in this sample, in addition to the impact of a cancer diagnosis on information retention. ${ }^{53}$ However, men's past and current perceptions of how their diagnosis and decisions were made still affect them, and are meaningful and relevant to understand.

\section{CONCLUSION}

Widespread overdiagnosis of prostate cancer remains an important health problem. ${ }^{2}$ The immense psychosocial consequences of a potentially unnecessary diagnosis must be taken into account in any discussions and decisions about PSA screening. These findings underscore the need to respect the ethical principle of autonomy by supporting men to make informed decisions about both screening and treatment in a clinical situation laden with so many uncertainties. Ultimately, the way to address the psychosocial burden of overdiagnosis and overtreatment of localised prostate cancer (especially low risk prostate cancer) is to better inform men and move decision making upstream, prior to diagnosis and prior to screening. More efforts to support informed choice and shared decision making at the point of PSA testing are needed.

Acknowledgements The authors would like to thank all men for their participation in this research.

Contributors $\mathrm{KM}, \mathrm{AB}, \mathrm{RM}, \mathrm{JH}$ and $\mathrm{BN}$ conceived the study and were involved in designing the study, developing the methods and drafting of the manuscript. $\mathrm{KM}$ and $\mathrm{AB}$ obtained funding and are Cls on the NHMRC funded project grant. $\mathrm{KM}, \mathrm{JH}$ and $\mathrm{BN}$ conducted the interviews, $\mathrm{KP}$ was involved in data analysis and drafting of the manuscript. These authors had full access to study data, and take responsibility for the integrity of the data and the accuracy of the data analysis. All authors contributed to the interpretation of the analysis and critically revised the manuscript.

Funding This work was supported by an Australian National Health and Medical Research Council (NHMRC) Programme Grant 1113532 and Centre for Research Evidence Grant no 1104136. KM is supported by an NHMRC Principle Research Fellowship 1121110.

Disclaimer The funder had no role in the design or conduct of the study; in the collection, analysis and interpretation of the data or in the preparation or approval of the manuscript.
Competing interests KM is supported by a NHMRC Principle Research Fellowship no 1121110. KM, RM, AB, BK, KP are involved in organising the not-for-profit international Preventing Overdiagnosis conference

Patient consent for publication Not required.

Ethics approval Ethical approval was granted by the University of Sydney Human Research Ethics Committee (Project No.: 2015/736).

Provenance and peer review Not commissioned; externally peer reviewed.

Data sharing statement № additional data are available.

Open access This is an open access article distributed in accordance with the Creative Commons Attribution Non Commercial (CC BY-NC 4.0) license, which permits others to distribute, remix, adapt, build upon this work non-commercially, and license their derivative works on different terms, provided the original work is properly cited, appropriate credit is given, any changes made indicated, and the use is non-commercial. See: http://creativecommons.org/licenses/by-nc/4.0/.

\section{REFERENCES}

1. Bell KJ, Del Mar C, Wright G, et al. Prevalence of incidental prostate cancer: A systematic review of autopsy studies. Int $J$ Cancer 2015;137:1749-57.

2. Moyer VA. on behalf of the U.S. Preventive Services Task Force. Screening for prostate cancer: U.S. Preventive Services Task Force recommendation statement. Ann Intern Med 2012;157:120-34.

3. Moynihan R, Doust J, Henry D. Preventing overdiagnosis: how to stop harming the healthy. BMJ 2012;344:e3502.

4. Bell N, Connor Gorber S, Shane A, et al. Canadian Task Force on Preventive Health Care. Recommendations on screening for prostate cancer with the prostate-specific antigen test. CMAJ 2014;186:1225-34

5. UK National Screening Committee. UK NSC prostate cancer recommendation 2016 www.screening.nhs.uk/prostatecancer.

6. Tang VL, Shi Y, Fung K, et al. Clinician Factors Associated With Prostate-Specific Antigen Screening in Older Veterans With Limited Life Expectancy. JAMA Intern Med 2016;176:654-61.

7. Drazer MW, Huo D, Eggener SE. National Prostate Cancer Screening Rates After the 2012 US Preventive Services Task Force Recommendation Discouraging Prostate-Specific Antigen-Based Screening. J Clin Oncol 2015;33:2416-23.

8. Stamey TA, Caldwell M, McNeal JE, et al. The prostate specific antigen era in the United States is over for prostate cancer: what happened in the last 20 years? J Urol 2004;172(4 Pt 1):1297-301.

9. Welch HG, Black WC. Overdiagnosis in cancer. $J$ Natl Cancer Inst 2010;102:605-13.

10. Cooperberg MR, Carroll PR. Trends in Management for Patients With Localized Prostate Cancer, 1990-2013. JAMA 2015;314:80-2.

11. Evans SM, Millar JL, Davis ID, et al. Patterns of care for men diagnosed with prostate cancer in Victoria from 2008 to 2011. Med J Aust 2013;198:540-5.

12. Donovan JL, Hamdy FC, Lane JA, et al. Patient-Reported Outcomes after Monitoring, Surgery, or Radiotherapy for Prostate Cancer. $N$ Engl J Med 2016;375:1425-37.

13. American Urological Association. Guideline for the management of clinically localized prostate cancer: 2007 update. https://www. auanet.org/common/pdf/education/clinical-guidance/ProstateCancer.pdf (Accessed 14 Jul 2016).

14. Prostate Cancer Foundation of Australia and Cancer Council Australia. PSA Testing and Early Management of Test-detected Prostate Cancer: Clinical Practice Guidelines, 2016.

15. National Comprehensive Cancer Network (NCCN). NCCN clinical practice guidelines in oncology: prostate cancer. Version 2014;2 http://www.nccn.org/professionals/physician_gls/pdf/prostate.pdf.

16. Heidenreich $\mathrm{A}$, Bellmunt J, Bolla $\mathrm{M}$, et al. EAU guidelines on prostate cancer. Part 1: screening, diagnosis, and treatment of clinically localised disease. Eur Urol 2011;59:61-71.

17. Hamdy FC, Donovan JL, Lane JA, et al. 10-Year Outcomes after Monitoring, Surgery, or Radiotherapy for Localized Prostate Cancer. N Engl J Med 2016;375:1415-24.

18. $\mathrm{Xu}$ J, Neale AV, Dailey RK, et al. Patient perspective on watchful waiting/active surveillance for localized prostate cancer. J Am Board Fam Med 2012;25:763-70.

19. Davison BJ, Breckon E. Factors influencing treatment decision making and information preferences of prostate cancer patients on active surveillance. Patient Educ Couns 2012;87:369-74.

20. Davison BJ, Oliffe JL, Pickles T, et al. Factors influencing men undertaking active surveillance for the management of low-risk prostate cancer. Oncol Nurs Forum 2009;36:89-96. 
21. Chapple A, Ziebland S, Herxheimer A, et al. Is 'watchful waiting' a real choice for men with prostate cancer? A qualitative study. BJU Int 2002;90:257-64.

22. Holmboe ES, Concato J. Treatment decisions for localized prostate cancer: asking men what's important. J Gen Intern Med 2000;15:694-701.

23. Saunders B, Sim J, Kingstone T, et al. Saturation in qualitative research: exploring its conceptualization and operationalization. Qual Quant 2018;52:1893-907.

24. Ritchie JSL, O'Connor W. Carrying out qualitative analysis. Qualitative research practice: a guide for social science students and researchers. London: Sage, 2003:219-62.

25. Wilt TJ, Jones KM, Barry MJ, et al. Follow-up of prostatectomy versus observation for early prostate cancer. $N$ Engl J Med 2017;377:132-42.

26. Jang JW, Drumm MR, Efstathiou JA, et al. Long-term quality of life after definitive treatment for prostate cancer: patient-reported outcomes in the second posttreatment decade. Cancer Med 2017;6:1827-36.

27. Sorum PC, Mullet E, Shim J, et al. Avoidance of anticipated regret: the ordering of prostate-specific antigen tests. Med Decis Making 2004;24:149-59.

28. Pickles K, Carter SM, Rychetnik L. Doctors' approaches to PSA testing and overdiagnosis in primary healthcare: a qualitative study. BMJ Open 2015;5:e006367.

29. Davis K, Haisfield L, Dorfman C, et al. Physicians' attitudes about shared decision making for prostate cancer screening. Family Medicine-Kansas City 2011;43:260.

30. Haines I. The scandal of prostate cancer management in Australia. MJA InSight 2016.

31. Hoffman RM, Lewis CL, Pignone MP, et al. Decision-making processes for breast, colorectal, and prostate cancer screening: the DECISIONS survey. Med Decis Making 2010;30:53-64.

32. Holmes-Rovner M, Srikanth A, Henry SG, et al. Decision aid use during post-biopsy consultations for localized prostate cancer. Health Expect 2018;21:279-87.

33. Scherr KA, Fagerlin A, Hofer T, et al. Physician Recommendations Trump Patient Preferences in Prostate Cancer Treatment Decisions. Med Decis Making 2017;37:56-69.

34. Holmes-Rovner M, Montgomery JS, Rovner DR, et al. Informed decision making: Assessment of the quality of physician communication about prostate cancer diagnosis and treatment. Med Decis Making 2015;35:999-1009.

35. Pickles K, Carter SM, Rychetnik L, et al. Goals, informationgiving and understanding: a grounded theory study of Australian doctors' varied communication about PSA testing. BMJ Open 2018;8:e018009.

36. Ghanouni A, Renzi C, Waller J. Improving public understanding of 'overdiagnosis' in England: a population survey assessing familiarity with possible terms for labelling the concept and perceptions of appropriate terminology. BMJ Open 2018;8:e021260.

37. Gigerenzer G, Mata J, Frank R. Public knowledge of benefits of breast and prostate cancer screening in Europe. J Natl Cancer Inst 2009;101:1216-20.
38. Moynihan R, Nickel B, Hersch J, et al. What do you think overdiagnosis means? A qualitative analysis of responses from a national community survey of Australians. BMJ Open 2015;5:e007436.

39. Loeb S, Curnyn C, Fagerlin A, et al. Qualitative study on decisionmaking by prostate cancer physicians during active surveillance. BJU Int 2017;120:32-9.

40. Wegwarth O, Gigerenzer G. Less is more: Overdiagnosis and overtreatment: evaluation of what physicians tell their patients about screening harms. JAMA Intern Med 2013;173:2086-8.

41. Hoffmann TC, Del Mar C. Patients' expectations of the benefits and harms of treatments, screening, and tests: a systematic review. JAMA Intern Med 2015;175:274-86.

42. McCaffery KJ, Jansen J, Scherer LD, et al. Walking the tightrope: communicating overdiagnosis in modern healthcare. BMJ 2016;352:i348.

43. Rychetnik L, Doust J, Thomas R, et al. A Community Jury on PSA screening: what do well-informed men want the government to do about prostate cancer screening--a qualitative analysis. BMJ Open 2014;4:e004682.

44. Hoffman RM, Lo M, Clark JA, et al. Treatment decision regret among long-term survivors of localized prostate cancer: Results from the prostate cancer outcomes study. J Clin Oncol 2017;35:2306-14.

45. Davies L, Hendrickson CD, Hanson GS. Experience of us patients who self-identify as having an overdiagnosed thyroid cancer: a qualitative analysis. JAMA Otolaryngol Head Neck Surg 2017;143:663.

46. Egger SJ, Calopedos RJ, O'Connell DL, et al. Long-term psychological and quality-of-life effects of active surveillance and watchful waiting after diagnosis of low-risk localised prostate cancer Eur Urol 2018;73.

47. Loeb S, Bruinsma SM, Nicholson J, et al. Active surveillance for prostate cancer: a systematic review of clinicopathologic variables and biomarkers for risk stratification. Eur Urol 2015;67:619-26.

48. Weerakoon M, Papa N, Lawrentschuk N, et al. The current use of active surveillance in an Australian cohort of men: a pattern of care analysis from the Victorian Prostate Cancer Registry. BJU Int 2015;115 Suppl 5(S5):50-6.

49. Nair-Shalliker V, Bang A, Weber M, et al. Factors associated with prostate specific antigen testing in Australians: Analysis of the New South Wales 45 and Up Study. Sci Rep 2018;8:4261.

50. Vetterlein MW, Dalela D, Sammon JD, et al. State-by-state Variation in Prostate-specific Antigen Screening Trends Following the 2011 United States Preventive Services Task Force Panel Update. Urology 2018;112:56-65.

51. Berger ZD, Yeh JC, Carter HB, et al. Characteristics and experiences of patients with localized prostate cancer who left an active surveillance program. Patient 2014;7:427-36.

52. Oliffe JL, Davison BJ, Pickles T, et al. The self-management of uncertainty among men undertaking active surveillance for low-risk prostate cancer. Qual Health Res 2009;19:432-43.

53. Gabrijel S, Grize L, Helfenstein E, et al. Receiving the diagnosis of lung cancer: patient recall of information and satisfaction with physician communication. J Clin Oncol 2008;26:297-302. 